\title{
ALGUNAS CONSIDERACIONES SOBRE LA REFORMA CONSTITUCIONAL: GARANTÍA DE PERMANENCIA O RUPTURA DE CONSENSO*
}

\author{
Considerations on constitutional reform: \\ Guarantee of permanence or rupture of consensus
}

\author{
M. ${ }^{a}$ Victoria García-Atance García de Mora \\ Profesora Titular de Derecho Constitucional \\ Universidad Nacional de Educación a Distancia \\ mgarcia-atance@der.uned.es
}

doi: http://dx.doi.org/10.18543/ed-65(2)-2017pp85-118

Recibido: 03.11.2017

Aceptado: 28.11.2017

\section{Resumen}

La finalidad de la función de reforma constitucional, es la de compatibilizar la tendencia irrenunciable al cambio, al que se encuentran impulsados los ordenamientos constitucionales por la inevitable e imparable evolución político-social y a la vez su permanencia en cuanto que, como texto fundamental en el que cristaliza la decisión política de una sociedad, exige su consolidación. En el presente trabajo se plantean algunos puntos en torno a determinados aspectos de la actividad de reforma tales como la titularidad de la iniciativa de la reforma constitucional, así como la conveniencia o inoportunidad de la misma, la organización territorial del

* Cómo citar / Citation 'Chicago-Deusto' (Autor-fecha / Author-date / Lista de referen-

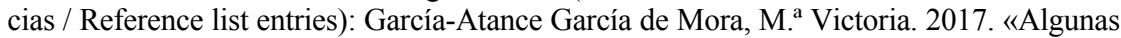
consideraciones sobre la reforma constitucional: garantía de permanencia o ruptura de consenso». Estudios de Deusto 65, n. ${ }^{\circ}$ 2: 00-00. doi: http://dx.doi.org/10.18543/ed-65(2)2017pp85-118. 
Estado y el grave problema catalán que suscitan en la actualidad una profunda reflexión.

\title{
Palabras clave
}

Reforma constitucional, iniciativa legislativa popular, mutación constitucional, supresión constitucional.

\begin{abstract}
The purpose of the constitutional reform function is to reconcile the irrevocable tendency to change, to which the constitutional orders are driven by the inevitable and unstoppable political-social evolution and at the same time its permanence in that, as a fundamental text in the that crystallizes the political decision of a society, requires its consolidation. In the present work some points are raised around certain aspects of the reform activity such as the ownership of the initiative of the constitutional reform, as well as the convenience or inopportune of it, the territorial organization of the State and the serious Catalan problem that currently provoke a deep reflection.
\end{abstract}

\section{Keywords}

Constitutional reform, popular legislative initiative, constitutional change, constitutional suppression. 
Sumario: 1. Introducción. 2. Controversia en la dialéctica 'PERMANENCIA-CAMBIO'. 2.1. La tensión existente de las constituciones escritas y rigidas entre la permanencia y el cambio. 2.2. Superación de la tensión permanencia-cambio. 3. REFORMA CONSTITUCIONAL: CONCEPTO, JUSTIFICACIÓN Y FUNDAMENTO JURÍDICO. 3.1. Concepto de reforma constitucional. 3.2. Justificación de la reforma. 3.3. Fundamento jurídico de la reforma. 4. DifERENCIACIÓN CONCEPTUAL ENTRE LA ACTIVIDAD CONSTITUIDA DE REFORMA Y OTROS Supuestos de VAriaciones en la Constitución. 4.1. Poder de reforma y autolimitación del poder constituyente. 4.2. Diferenciación terminológica y conceptual de las alteraciones de la constitución diferentes de la reforma. 4.2.1. La destrucción de la constitución. 4.2.2. La supresión constitucional. 3.2.3. El quebrantamiento de la constitución. 5. LA REFORMA CONSTITUCIONAL COMO INSTRUMENTO DE GARANTÍA CONSTITUCIONAL: FACTOR DETERMINANTE EN LA PROTECCIÓN DE LA FÓRMULA DE IDENTIDAD. 5.1. Justificación de la reforma constitucional como instrumento de garantía no jurisdiccional. 6. Algunas Reflexiones sobre la CONVENIENCIA DE CAMBIO FORMAl EN la Constitución De 1978. 6.1. Ponderación de la oportunidad de modificación de la constitución. 6.2. Relación de temas de inclusión y exclusión de una eventual modificación de la constitución. 7. ESPECIAL REFERENCIA A LA EXCLUSIÓN DE LA INICIATIVA POPULAR EN LA ACTIVIDAD DE REFORMA CONSTITUCIONAL COMO POSIBLE OBJETO DE MODIFICACIÓN. 7.1. Sujetos titulares del poder de iniciativa de reforma constitucional. 7.2. Método mixto de iniciativa de reforma. 7.3. Rigidez en la iniciativa de reforma por vía reglamentaria. 8. TITULARIDAD DE LA INICIATIVA DE REFORMA. 8.1. Iniciativa del Gobierno. 8.1.1. La singular intervención del Consejo de Estado en la iniciativa de reforma. 8.2. Iniciativa del Congreso y del Senado. 8.3. Iniciativa de las Asambleas de las CCAA. 8.4. Exclusión de la iniciativa popular. 8.5. Conclusión sobre la exclusión de iniciativa popular en la actividad de la reforma. 9. CONSIDERACIONES SOBRE LA CONVENIENCIA O INOPORTUNIDAD DE REFORMA CONSTITUCIONAL. 10. LA ORganización TERritorial de Estado. El GRAVE PROBLEMA CATAlÁn. 10.1. Posible modificación informal de la previsión constitucional en el caso catalán. 10.2. Seguridad jurídica y límites de la modificación informal de la Constitución. BIBLIOGRAFÍA.

\section{INTRODUCCIÓN}

La andadura de 40 años de vigencia constitucional supone una importante reflexión en torno al análisis de la eficacia de la Norma fundamental, en su objetivo de convivencia y libertad en una democracia representativa, ante las nuevas circunstancias que han cambiado el perfil de nuestra sociedad. Esto 
es, se han producido hechos relevantes, inexistentes en la etapa constituyente, como la unificación europea, la caída del muro de Berlín, la guerra de Irak, la amenaza del terrorismo, el progreso biotecnológico, etc., que requieren un replanteamiento sobre el grado de dinamismo de nuestro ordenamiento constitucional al compás de las necesidades de la nueva sociedad tras 40 años.

El presente trabajo analiza algunos de los posibles cauces para acoplar el texto constitucional al escenario de la nueva realidad socio-política.

Debido a la supremacía de la Constitución y la caracterización de cualquier cambio de su normatividad, cualquier alteración de la misma, como afirma De Cabo, «tiene tal trascendencia que exige la utilización de categorías fundamentales de la Teoría y el Derecho constitucional, de tal complejidad, que terminan configurándose como parámetro de muchas otras, y desde luego, del orden constitucional, lo que supone una permanente vigencia y permanente cambio, a través de nuevas respuestas» (De Cabo, 2003: 9). En definitiva, se trata de subsistir evolucionando.

Así, todo Estado que pretenda organizarse bajo un mínimo de juridicidad reconoce unos principios insoslayables para definirse conforme a una estructura jurídico-positiva, de tal modo que los cambios que pueda introducir en el ordenamiento constitucional sean congruentes con el mismo.

Es por ello que la Constitución, como Lex Superior, obliga al poder legislativo y en general a todos los poderes constituidos mientras no opere de nuevo su poder constituyente, o se reforme la misma. Y, aún así, en tanto que poder constituido, siempre quedará condicionada su modificación a que las reformas que se verifiquen, por una parte, no contradigan las directrices sustantivas y basilares, estén éstas o no reflejadas en el Código fundamental. Por otro lado, la modificación queda condicionada al respeto que la actividad de reforma debe proyectar respecto al elemento identificador -«Presuposto essenciale e irreductibile» que definía Crisafulli (Crisafulli, 1930: XVII)propio de cada orden constitucional, debiéndose compatibilizar los elementos que alientan la función reformadora: la evolución con la permanencia. Solo así la función de revisión actuará como auténtico instrumento de defensa y garantía constitucional, que es uno de los objetivos que cumple también la función reformadora. Como veremos más tarde, de no ser así, la Constitución corre el riesgo de sucumbir. Esto sucedería, por otro lado, con las constituciones pétreas (Sempere, 1907) ${ }^{1}$ que suponen el exponente máximo del deseo de salvaguardar el texto y que, sin embargo, resultan ser la vía más idónea para que la Norma Fundamental y su organización política fracasen, generando además acontecimientos revolucionarios.

${ }^{1}$ Al lado de las constituciones rígidas y flexibles, Sempere designa como un tertium genus aquellas que no prevén cláusula alguna de revisión. 


\section{CONTROVERSIA EN LA DIALÉCTICA 'PERMANENCIA- CAMBIO'.}

El instituto de la reforma constitucional, orientado a suplir las deficiencias que la Norma Fundamental puede albergar, no debe ser instrumentalizado para provocar una posible crisis política (Spagna Musso 1979:143), cuya solución supusiera la eventual instauración de un nuevo orden constitucional completamente diferente, por producir, no una reforma, sino la desconstitucionalización del sistema político de la comunidad.

El constitucionalismo revolucionario ejemplarizó la pretensión de la permanencia de los textos constitucionales para asegurar a las futuras generaciones los hitos conseguidos por el liberalismo constitucional. Este deseo de permanencia se constata en el constitucionalismo moderno, al dotar a las constituciones rígidas de un dispositivo para su reforma al objeto de permitir la adaptación de las mismas al continuo mutar social, posibilitando con ello la subsistencia de la Ley Superior. Así pues se aplica la idea definida en la Constitución francesa de 1793, cuyo artículo 28 estableció: «Un pueblo tiene el derecho de cambiar, revisar y reformar su Constitución. Una generación no puede someter a sus leyes a las generaciones futuras». Se generalizó así la conciencia de que no puede entenderse la constitución como ley permanente y eterna, básicamente por tres motivos:

- Por la necesidad de adaptación a la realidad, sometida a continua evolución.

- Por el envejecimiento de la norma por paso del tiempo y del cambio semántico.

- Por las lagunas que se detectan en la aplicación práctica de la constitución.

\subsection{La tensión existente de las constituciones escritas y rígidas entre la permanencia y el cambio.}

Frente al caso británico (Lucas Verdú, 1977:646) que, por no existir un código fundamental escrito, es sumamente permeable en su adaptación a las nuevas necesidades, las constituciones escritas y rígidas reflejan de manera patente la tensión (Bryce, 2015) entre la permanencia y el cambio constitucional. Se pone así de relieve la tendencia de todo ordenamiento a conciliar el carácter estático de sus normas originarias junto con las orientaciones de las direcciones políticas que los órganos constitucionales formulan bajo el impulso de las fuerzas sociales.

Pero más allá de la necesaria adaptación, la tensión que subyace en toda función revisora, permanencia-cambio, se intensifica cuando la adaptación 
del texto, tuviera como objeto una transformación que afectara a alguno de los principios sustantivos (Lucas Verdú, 1977:428) que identifican y definen ese preciso ordenamiento jurídico-constitucional.

\subsection{Superación de la tensión permanencia-cambio.}

El concepto estabilidad-cambio, ¿asume sentido quimérico en el ámbito constitucional? , ¿cabe conciliar la permanencia a la que tiende todo texto constitucional con su propia transformación? y, si es así, ¿hasta qué punto puede predicarse la permanencia de un texto que altera sus postulados básicos?

Entendemos que hablar de permanencia alude a la idea de subsistencia del núcleo que es esencial de la constitución, es decir, que las reformas que haya de experimentar el texto permitan seguir reconociéndolo, con lo que las características propias que lo determinan, en este caso la dialéctica permanencia-cambio, aportaría verdadera estabilidad (Morlino, 1985). Esto es, para que un régimen constitucional sea estable, es decir, que la tensión permanencia-cambio se trueque en estabilidad, es preciso que se realicen transformaciones internas, pero asumiendo la continuidad de ciertas estructuras. De no ser así, se produciría un desequilibrio entre la constitución subyacente y los nuevos postulados de la función reformadora material (Mortati, 1940:204), produciéndose una brecha que agudizaría la tensión dialécticapermanencia, mientras que si, por el contrario, ambas discurren al punto de acoplarse, la tensión permanencia-cambio no suscitará desequilibrio alguno, más allá del derivado de lo que supone la simple integración de la reforma, pero sin desviarse de las decisiones constituyentes asumidas en su momento en la Constitución.

\section{REFORMA CONSTITUCIONAL: CONCEPTO, JUSTIFICACIÓN Y FUNDAMENTO JURÍDICO.}

\subsection{Concepto de reforma constitucional.}

La Constitución, en sentido formal, exige que su modificación sea más difícil, según su grado de rigidez, que cualquier otra modificación que afectara a una ley ordinaria. Lo anterior es predicable sólo de las constituciones escritas, que asumen la forma de un Estatuto, frente a lo que sucede con Estados que carecen de documento formal de constitución, como el caso de Gran Bretaña, donde no se diferenciaría de las demás leyes ordinarias.

En la mayoría de los casos en los que existe una constitución formal, las leyes constitucionales, como señala Kelsen, se distinguen de las ordinarias, tanto por su promulgación, como por su abrogación y reforma (Kelsen, 1979: 147). Así, ésta será más difícil, por contemplar un procedimiento especialmente 
solemne para su creación y, además, sus efectos han de proyectarse de igual modo en el supuesto de reformar, con lo que se distingue de nuevo de las demás leyes ordinarias.

Entendida así la Constitución como el código político en que un país plasma su existencia política, pretenderá un mínimo de estabilidad y seguridad que se traduce en que sus modificaciones se realicen con especiales esfuerzos, sin que por ello se impida su adecuación a las nuevas exigencias políticas.

Ahora bien, ¿cómo realizar los cambios constitucionales para no desestabilizar el equilibrio estabilidad-permanencia que toda constitución debe mantener en la esfera de su supremacía? Los teóricos del siglo XVIII no aplicaron un criterio afín, siguiendo tres posibles vías que, conforme a Esmein (Esmein, 1921: 568), cabe reformular en tres grupos:

a) La exigencia de que la modificación del código fundamental se acometiera con el consentimiento unánime de los ciudadanos, conforme al principio de identidad que postulara Rousseau, si bien la dificultad de esta vía, tornaba impracticable revisión alguna de toda norma fundamental.

b) La segunda opción fue ofrecida por Sieyès, según la cual las leyes constitucionales vinculan a los poderes constituidos, pero no están por encima de la nación de la que han emanado y que puede, siempre, cambiar la Constitución en completa libertad. Sieyès extendería esta libertad a los 'representantes', conforme al mandato representativo «un corps de representants ordinoirs suplée à l'Assemblée de la Nation». De esta forma, los cambios del código fundamental pasarían de situar su centro de gravedad en la Nación, a recaer en los representantes de la misma.

c) Sin embargo, la alternativa que más eco obtuvo, fue aquella con base en la cual los textos constitucionales debían ser revisados por la misma autoridad y procedimiento que ella misma determinó, conforme al postulado de Rousseau (Esmein, 1921: 611)2.

Debido pues a las transformaciones económicas y sociales imperantes de un país, la nación experimenta la necesidad viva de modificar su constitución para que ésta sea real y efectiva y no una simple hoja de papel mojado (Loewenstein, 1965:185). Por ello, la mayoría de los sistemas constitucionales

${ }^{2}$ «Il est contre la nature du corps social de composer des lois qui'l ne puisse revoquer, mais il n'est contre la nature ni contre la raison qu'il ne puisse revoquer ces lois avec la même solennité qui'l'a mit pour les établir». 
están dotados de una institución jurídico constitucional que es el instituto de reforma.

\subsection{Justificación de la reforma.}

Por perfecto que resulte el acto constituyente, es imposible que su obra vaya a ser eterna. La experiencia y el tiempo sugerirán nuevas reformas convenientes en el texto constitucional, siendo indispensables integrarlas en la norma superior. Tal formulación, como señaló Madison, debía proteger por igual contra una excesiva facilidad, que convirtiera la Constitución en un Estatuto demasiado variable, así como contra la exagerada dificultad que la condenara a defectos manifiestos, y perpetuando además con ello, la tensión permanencia-cambio (Madison, 1957: 187).

La justificación, en síntesis, de la reforma constitucional viene definida porque las cualidades de excelencia de una Norma fundamental extrapolada en el tiempo, no justifica la pretensión de su perdurabilidad. Así lo entendió la Constitución francesa de 1791, al reservar a la nación el derecho a cambiar la constitución, revocando el poder que ella daba al rey: «L'Assemblée constituante déclare que la nation a le droit imprescriptible de changer sa Constitution» (Título VII, Art. $1^{\circ}$ ).

\subsection{Fundamento jurídico de la reforma.}

El establecimiento de una Constitución pone en marcha la manifestación del Poder Constituyente, originario e incondicionado, mientras que reformar una Constitución activa un Poder de naturaleza diferente, pues se trata de un poder derivado, no pudiendo aspirar a otra forma de actividad que la establecida en la norma constitucional. Hunde así sus raíces en la propia regulación jurídico-constitucional para introducir las modificaciones pertinentes en el texto como señala Herrero y Rodríguez de Miñón (Herrero y Rodríguez de Miñón, 2016:20). Sin embargo, esta afirmación sencilla no deja de suscitar controversia con motivo tanto de su grado de extensión, como por el contenido de la misma (De Vega, 1985:228).

En definitiva, tal diatriba refleja de nuevo la tensión subyacente en este instituto relativa a su aplicación en un estricto sentido jurídico o como instrumento que trasciende a la propia función revisora que se proyecta como una 'manipulación' de la misma, desbordando su carácter jurídico constitucional derivado y arrogándose unas atribuciones que no le competen. Se reconoce, así, en la cláusula de reforma, el dispositivo que pone en marcha el proceso que se sigue para producir cambios en el texto constitucional para adaptarla a las nuevas contingencias de la sociedad. 


\section{DIFERENCIACIÓN CONCEPTUAL ENTRE LA ACTIVIDAD CONSTITUIDA DE REFORMA Y OTROS SUPUESTOS DE VARIACIONES EN LA CONSTITUCIÓN.}

Partiendo de que una Constitución ha de revisarse para acomodarse a la realidad y de que esta actividad se encuentra en la propia Constitución, se entiende que la modificación ha de regirse por los cauces jurídicos previstos, como dice Ruiz del Castillo, el Derecho futuro debe brotar del Derecho actual, desenvolviéndose en continuidad todo el derecho actual (Ruiz del Castillo, 1939).

La admisibilidad de reforma total por parte algunos ordenamientos -entre ellos el nuestro- no obsta para considerar que, aunque desde un punto de vista jurídico, sea impecable por estar así previsto en la constitución, sin embargo sea criticable desde la óptica de la legitimidad sobre la que reposa el poder constituyente.

Introducir determinados cambios identificadores de la formula de identidad de un ordenamiento constitucional, o bien cambiar de forma total la constitución, invocando el principio de legalidad, no deja de constituir una maniobra atentatoria contra la legitimidad del poder constituyente originario (De Vega, 1985:228). Y es que, como afirma Friedrich (Friedrich, 1975:283), el poder constituyente sólo puede ser ejercido por un sector capaz de reemplazar el orden establecido por una nueva constitución.

Así, la reforma que conforme a las prescripciones reguladas jurídicamente en el texto, afectara a aspectos que incumben a la actividad constituyente, sería acorde con la legalidad del derecho positivo, pero discutible desde la óptica de que subvierte el orden de prioridad entre el poder constituyente -que representa la legitimidad de quien está facultado a hacer o no hacer- y el poder de reforma -representado por la legalidad como señala Duverger, y cuyo objeto debe girar en torno a la continuidad del ordenamiento (Duverger 1980:41).

\subsection{Poder de reforma y autolimitación del poder constituyente.}

Desde esta consideración, al igual que en la constitución se regulan los distintos poderes del Estado, aparece también ordenado el poder de revisión, cuya misión no es otra que la de operar jurídicamente los cambios cuando las circunstancias lo requieran. El interrogante que en todo caso planea es ¿puede el poder constituyente autolimitarse a sí mismo como se plantea De Vega? (De Vega, 1985:71). El poder constituyente de un día no puede condicionar el poder constituyente del mañana, que es igualmente soberano y no sometido a limitación alguna. En otras palabras, convenimos con De Vega, en que la reforma constitucional configura una operación jurídica que no rompe con la idea de continuidad considerando que el poder constituyente 
permanece. Ahora bien, ¿cómo explicar la continuidad y permanencia del poder constituyente ante algún supuesto de los contemplados en el art. 168 $\mathrm{CE}$, que pueden alterar la identidad de la constitución o incluso su reforma total? ¿Puede, en rigor, calificarse esa actividad como una reforma constitucional? Creemos que si se trata de una reforma total, realmente sería una nueva manifestación del poder constituyente $\mathrm{y}$, por tanto, debiera actuar de manera absolutamente libre y omnímoda, con lo que no estaría sujeto a condición alguna respecto a lo regulado y previsto en el artículo que contempla dicha actividad de reforma. Esto es así porque a lo que al final se llega es a una situación en la que se habría suprimido la constitución, rompiéndose con la idea de continuidad, que es, en definitiva, el fundamento que justifica la actividad revisora. Con la reforma total de la constitución se origina una actividad revolucionaria, una nueva manifestación del poder constituyente y, como tal, no tiene por qué quedar sujeta a tipo alguno de regulación jurídicoconstitucional, cuya pretensión, como señala De Vega, es la de la continuidad de la constitución (De Vega, 1985).

\subsection{Diferenciación terminológica y conceptual de las alteraciones de la constitución diferentes de la reforma.}

En conexión con la problemática en el ámbito de la supremacía del poder constituyente sobre el constituido, hay que diferenciar terminológica y conceptualmente los distintos supuestos que alteran un orden constitucional pero que, por no suponer una continuidad del mismo, difieren de la naturaleza de la figura de la reforma constitucional y cuya actividad trasciende de la de simple reforma.

Schmitt propuso una tipología de estos supuestos de alteración conforme a diversos cambios en el texto constitucional, pero que no implican propiamente la reforma del mismo (Schmitt, 1982: 155).

\subsubsection{La destrucción de la constitución.}

Supone un cambio de tal entidad en el orden existente que comporta la supresión de la constitución y no sólo de alguna regulación legal, acompañando a tal acontecimiento, a su vez, la supresión del poder constituyente en que el orden anterior se basó. Tal sería el caso de una revolución democrática en la que, subvirtiendo el orden, se suprime también el poder constituyente, como aconteció en Francia en 1789 y 1793, cuando se suprimió por vía revolucionaria la monarquía. Igualmente puede darse el caso opuesto, esto es, la supresión por vía de una revolución o golpe de Estado del poder constituyente de la nación, produciéndose en ambos supuestos cambio en el poder 
constituyente y cambio de la constitución, siendo la ruptura del orden absoluta y sin continuidad.

\subsubsection{La supresión constitucional.}

La supresión es, en parte, afín al anterior y se da cuando la continuidad del orden se resquebraja por la abolición o supresión de la constitución pero subsistiendo el poder constituyente. Tal sería el supuesto de una reforma total, aunque consideramos que el término de reforma, aquí, es inadecuado porque, como vimos antes con De Vega, no hay continuidad de la constitución, que es lo que configura la esencia de la actividad reformadora. Al ser suprimida la norma fundamental, difícilmente puede seguir hablándose de continuidad jurídica como mantenían Posada y otros autores (Posada, 1929; Schmitt, 1982:155; Mortati, 1949:202). En consecuencia, cabe afirmar con los mencionados autores, que en el sistema constitucional pueden explicarse las supresiones de la constitución pero no las que se pudieran producir por el mecanismo de reforma, ya que, cuando se produce una autorruptura de la constitución, es el propio poder constituyente el que se activa, separándose de un poder constituido de reforma y no soberano, con lo que se diferenciaría así entre la actividad del poder constituyente y el poder de reforma.

\subsubsection{El quebrantamiento de la constitución.}

Por quebrantamiento de la norma constitucional se entiende un caso muy particular de alteración de ésta que se produce cuando son derogadas sus normas en casos determinados y a título excepcional, si bien manteniendo su vigencia y validez respecto a los demás supuestos. Se trata, pues, de una violación ocasional de la constitución, que comporta la excepcionalidad de las previsiones constitucionales. Esta circunstancia es difícilmente aceptable en un Estado de Derecho, como aduce Vera Santos, en el que la supremacía constitucional no puede ser excepcionada (Vera Santos, 2007:36).

\section{LA REFORMA CONSTITUCIONAL COMO INSTRUMENTO DE GARANTÍA CONSTITUCIONAL: FACTOR DETERMINANTE EN LA PROTECCIÓN DE LA FÓRMULA DE IDENTIDAD.}

La pregunta que se formulaba Schmitt ('¿quién debe ser el guardián de la constitución?') reflejaba la insuficiencia de la solución kelseniana de atribuir sólo a un tribunal de justicia la función de defensa de la Constitución (Schmitt, 1983:16).

En su intervención en la apertura de nuestro Tribunal Constitucional, de García-Pelayo aseveró: «El Tribunal Constitucional no es el único órgano 
encargado de velar y proteger la Norma Constitucional, ni la vía jurisdiccional el único camino para su defensa». Asimismo, como afirmó Tomas y Valiente, hay otras instituciones a las que la Constitución encarga la misión de defenderla: el Rey, las Cortes, el Gobierno, en determinados supuestos, las Fuerzas Armadas y el Defensor del Pueblo (Tomas y Valiente, 1982-83: 188).

La amplitud con la que se entiende la defensa de la constitución influye de manera decisiva para que la delimitación de instituciones implicadas sea de difícil concreción, como sugirió De Otto, atendiendo a los dos objetos de protección: el que deriva de una infracción de la constitución y el que se refiere a la garantía de permanencia del orden constitucional (De Otto, 1985:12).

\subsection{Justificación de la reforma constitucional como instrumento de garantía no jurisdiccional.}

Las prescripciones constitucionales son relevantes no por el simple hecho de regular competencias concretas, ni siquiera por definir funciones orgánicas, sino porque el Estado define con éstas su propia esencia, por lo que todo ordenamiento jurídico establece un instituto jurídico al que atribuye esa función garantizadora. Sin embargo, el hecho de que la vía jurisdiccional no agote la función de garantía (Smend, 1985:227), a la que está sujeta toda Norma Fundamental, hace obligada la justificación de la función de reforma como otro instrumento garantístico más.

El reconocimiento de instrumentos institucionales de defensa de la norma, de carácter plurivalente y no exclusivo de un sólo órgano, incluye al instituto de revisión, toda vez que establece una serie de condiciones específicas invocables y exigibles para su modificación, que configuran un medio idóneo para asegurar su estabilidad, y que se recogen en los procedimientos señalados para acometer dicha reforma.

Conforme a Mortati, la justificación de la reforma en tanto que instrumento de garantía, se explica con base en lo siguiente:

- Porque formando parte el propio procedimiento de revisión de la norma fundamental, difícilmente podría considerársele ajeno a la noción de garantía que la propia constitución encierra.

- Porque su propia función coadyuva a la garantía de la constitución.

- Porque la institución de reforma sirve de vía para sustraer del juez constitucional los propios actos del órgano de revisión.

- Por la ambivalencia de su función, capaz no sólo de verificar necesarias adaptaciones de la Norma, sino también de preservar su estabilidad.

Porque el propio agravamiento del procedimiento para su activación configura en sí mismo una función de garantía (Mortati, 1949:224). 
Así, no es otra la óptica desde la que cabe entender la institución de la reforma constitucional, sino como la fórmula consagrada por el constitucionalismo moderno para adaptar aquélla a las nuevas exigencias para permanecer conforme a una concepción normativa, decisionista e integradora (Herrero y Rodríguez de Miñón, 2016: 16).

\section{ALGUNAS REFLEXIONES SOBRE LA CONVENIENCIA DE CAMBIO FORMAL EN LA CONSTITUCIÓN DE 1978.}

Hemos visto con anterioridad que uno de los objetivos de la función del instituto de reforma es el de defensa de la constitución, función ésta que adquiere un significado teleológico, y que no se ciñe únicamente al estricto procedimiento del mismo, sino en ocasiones, su función de defensa va más allá de su activación para proceder a reformar la constitución. Así, esta función de defensa de la Norma se manifiesta no sólo en su activación como tal, sino también en la omisión de la misma cuando así lo aconseje la prudencia política, atendiendo a factores que concurren igualmente al carácter de defensa del ordenamiento constitucional. De este modo, habrá que tener en cuenta aspectos tales como la conveniencia, oportunidad del momento para su activación, cálculo de consenso entre las fuerzas políticas, etc., factores éstos que una mínima prudencia política aconseja valorar, al margen de los intereses más o menos partidistas que pudieran confluir en un momento dado por coyunturas de oportunismo político.

Por ello, las deficiencias que tiene nuestra Constitución no sólo precisarían para su solución de un consenso político como el que se logró en la transición, que hoy por hoy se presenta difícil, sino que precisa de la adhesión de la opinión pública al proyecto de reforma. Es decir, como sostiene Torres del Moral, hay que lograr el respaldo en cuanto a lo que se quiere hacer, qué instituciones reformar, qué garantías adoptar, cómo se quiere hacer y de los tiempos para acometerse en nuestro actual escenario político-social (Torres del Moral, 2017). En síntesis, se trataría de ponderar la viabilidad de la reforma y el beneficio estimable frente al alto coste para el sistema político durante un largo plazo de tiempo.

\subsection{Ponderación de la oportunidad de modificación de la constitución.}

En relación a la conveniencia de una modificación de la constitución, hay que plantearse tres cuestiones en el presente escenario político de nuestra sociedad:

- primero, si hay que reformarla;

- segundo, qué habría de ser reformado;

- tercero, cómo se haría la reforma. 
Respecto al primer supuesto, el envejecimiento constitucional, hay que decir que implica un doble efecto, positivo y negativo en todo orden fundamental. Así, por un lado, afianza el funcionamiento las instituciones, permite una previsibilidad jurídica sólida y genera un sentimiento de adhesión hacia ella, pero, de otro lado, pone de manifiesto que prescripciones que en su momento fueron adecuadas han quedado obsoletas y tal vez superadas y vacías de contenido. Se evidenciarían así defectos técnicos o situaciones superadas por la evolución de las propias instituciones, por lo que podrían incluso eliminarse, lo cual haría aconsejable su reforma, entendida ésta siempre desde la perspectiva de su función de defensa del ordenamiento constitucional. Por otro lado, hay que tener igualmente presente que una reforma puede ser contraproducente, más que beneficiosa, si ésta se acometiera sin tener una idea clara de lo que se quiere modificar y sin contar con el pertinente consenso, lo que puede originar el efecto contrario al de defensa de la constitución que asume el instituto de reforma.

Respecto al segundo supuesto, tanto desde la opinión pública como desde los, frecuentemente engañosos, programas electorales de los partidos políticos, se proclama, a veces sin no mucho fundamento, pero buscando réditos electorales, la necesidad de determinadas reformas en la Constitución. No seré yo quien niegue su conveniencia, pero sí que deben acometerse, como afirma Herrero y Rodríguez de Miñón, con base en un, muy prudente, triple criterio (Herrero y Rodríguez de Miñón, 2016:46):

- En primer lugar, no todas las reformas aún convenientes e incluso necesarias, han de tramitarse necesariamente por vía de la reforma formal prevista en la Constitución.

- En segundo término, la prudencia política aconseja que muchas de las modificaciones convenientes se hagan poco a poco, teniendo así más fácil una eventual rectificación, mejor que si se consolidara en la norma por vía de reforma formal (Torres del Moral, 2017).

- Finalmente, no todas las modificaciones de la Norma, por convenientes que sean, deben acometerse al mismo tiempo.

En relación al tercer supuesto, sería conveniente, para no estar en permanente proceso de revisión de la Norma, huir de propuestas singulares de revisión, ordenándolas, tal como sugiere Torres del Moral en paquetes de reforma que integraran grupos normativos concretos, como por ejemplo, uno que afectara a la representatividad, y en el que entraran diversos temas concernientes, como el fuero de los parlamentarios y de los miembros del gobierno, y también podría incorporarse en este paquete una más amplia 
relación de incompatibilidades de los senadores o de los miembros del gobierno, por ejemplo (Torres del Moral, 2017:7).

En un sistema democrático se aprecia la conexión institucional existente, que hace recomendable, que los cambios que conviene hacer ante las demandas que plantea la sociedad, puedan igualmente acometerse a través de una legislación subconstitucional (Torres del Moral, 2017: 11), de manera que se haga innecesaria o menos urgente la vía de reforma, particularmente en el actual escenario político, que considero poco propicio para lograr el adecuado consenso y la estabilidad política y constitucional.

De igual modo, las modificaciones que se acometieran habría que hacerlas con tal precisión que no afecte a ningún otro precepto que es válido en nuestra Constitución, precisamente por la condición de instituto de garantía no jurisdiccional y defensa de la constitución que aquél asume.

\subsection{Relación de temas de inclusión y exclusión de una eventual modificación de la constitución.}

Entre los distinto temas que, desde hace un tiempo, son objeto de propuesta de cambio en nuestra Constitución se encontrarían: el Senado, el sistema electoral, la cláusula de varonía, la sucesión de la Corona, el Estatuto de la familia real, el fuero de los parlamentarios, la administración de justicia, la legislación de partidos en materia de financiación y control democrático, los reglamentos parlamentarios, la investidura del Presidente de gobierno, la responsabilidad política individual de los ministros, la organización territorial del Estado, los estatutos de autonomía (atendiendo a la eventual subsistencia de sólo aquéllos que superen determinado número de habitantes), el propio procedimiento de reforma contemplado en los arts. 167 y $168 \mathrm{CE}^{3}$. Respecto a este extenso elenco, convendría precisar algunas consideraciones.

En primer lugar, entre las propuestas de reforma, habría algunas que, aunque convenientes, su análisis riguroso pone de manifiesto su inoportunidad de acometer hasta más adelante, al objeto de precisar la delimitación del alcance de la reforma, pues de poco serviría una revisión de la Norma que no concitase consenso.

En segundo lugar, otras demandas podrían acometerse sin necesidad de abrir un procedimiento de reforma que active el poder constituyente constituido, por ser su coste desproporcionado y por lo que supone de interinidad a la que queda sometido nuestro sistema político. Este sería el caso de un importante número de propuestas que podrían resolverse por otra vía como

${ }^{3}$ Este tema ha sido objeto de excelente estudio por un reconocido sector de la doctrina recientemente (Torres del Moral, 2017:20; Herrero y Rodríguez de Miñón, 2016:51). 
mediante una Ley orgánica o por modificación de los Reglamentos de las Cámaras.

Por otra parte, en sectores como la Administración de justicia, es ocioso pensar que sus defectos dependan del texto constitucional y quedaran resueltos reformando la Constitución, sino que es necesario, por el contrario, acometerse por la norma legal a la que remite el art $127 \mathrm{CE}$.

\section{ESPECIAL REFERENCIA A LA EXCLUSIÓN DE LA INICIATIVA POPULAR EN LA ACTIVIDAD DE REFORMA CONSTITUCIONAL COMO POSIBLE OBJETO DE MODIFICACIÓN.}

Conforme a un relevante sector de la doctrina (Burdeau, 1969:274), la problemática de la iniciativa de reforma confiere una importancia trascendental en orden a la interpretación de las características del sistema constitucional en su conjunto. Así, es más propio de regímenes autoritarios hacerla recaer en el gobierno y es más común a los eminentemente democráticos, dar clara, si no exclusiva, prevalencia al Parlamento.

El constituyente español ha conferido a la iniciativa la relevancia que se merece al dedicar a su regulación el artículo 166, conforme al cual, la iniciativa se ejercerá según lo previsto en los apartados 1 y 2 del artículo 87, según los cuales, la iniciativa corresponde al Gobierno, al Congreso, al Senado y a las Asambleas de las Comunidades Autónomas. Se atribuye, así, un trato común de la iniciativa, tratando a los legitimados para activar la función de reforma en plano de igualdad, independientemente del procedimiento que se adopte según los artículos 167 o 168. De esta manera, la iniciativa de reforma que se materialice por la vía del 168 no es más costosa (Vera Santos, 2007:200), lo que, sin embargo, en mi opinión, hubiera sido más coherente con la caracterización de este segundo procedimiento agravado.

\subsection{Sujetos titulares del poder de iniciativa de reforma constitucional.}

La diversidad de órganos concurrentes para iniciar un proceso de reforma, encierra una doble ventaja, de un lado porque la reforma se presente respaldada con mayor legitimidad, y de otro, se evita que al órgano único al que se hubiera reconocido la iniciativa de reforma, aplicara su situación de privilegio en su exclusivo interés (De Vega, 1985:128).

La iniciativa de reforma que contempla el ordenamiento opera a través del modelo de iniciativa compartida al que se refiere Burdeau, como base de la doble intervención gubernamental y legislativa, marginando, expresamente -artículo $166 \mathrm{CE}$ en conexión con el $87 \mathrm{CE}$ - la intervención popular. Así, aun reconociéndose ésta en vía legislativa ordinaria, se soslaya para el 
supuesto de reforma, lo que ha suscitado críticas en un amplio sector de la doctrina que ha considerado de cierta cicatería la intención del constituyente, al hurtar de ese modo la intervención del soberano en tema de tal envergadura, como es la revisión constitucional en fase de iniciativa, sin perjuicio de su intervención en el procedimiento propiamente dicho de reforma por vía de referéndum, ya sea facultativo (artículo $167 \mathrm{CE}$ ), ya obligatorio (168 CE).

\subsection{Método mixto de iniciativa de reforma.}

Este sistema mixto de iniciativa, propio de las constituciones modernas como señala Kelsen, aún reconociendo el principio de separación de poderes, reconocen capacidad legislativa al ejecutivo, tiene su manifestación inmediata para el proceso de elaboración de las leyes en general, y de revisión en particular, en que el ejecutivo comparte con el legislativo el derecho reconocido constitucionalmente de tomar la iniciativa en el proceso legislativo, siendo esta intervención del Gobierno en las tareas legislativas de general reconocimiento por parte de la mayoría de las constituciones modernas.

Las vías establecidas por el artículo $166 \mathrm{CE}$ respecto al $87 \mathrm{CE}$ para iniciar la reforma, determina ya $a b$ initio la diferencia con el procedimiento seguido en el legislativo ordinario en lo que respecta a la intervención popular, que sí prevé tal vía. Salvo esta excepción, no se desprende diferencia alguna entre la intervención que se ejercería para el caso de las leyes ordinarias y aquélla que se seguiría para los supuestos de reforma constitucional, sin perjuicio de la diferencia entre los diversos tipos de iniciativa en relación a los órganos que intervinieran y conforme a los Reglamentos de ambas Cámaras.

\subsection{Rigidez en la iniciativa de reforma por vía reglamentaria.}

Éstas diferencias no suponen una mayor rigidez en la fase de iniciativa. Así, los resortes en pro de la rigidez constitucional, deben entrar en vigor a raíz de haberse llevado a cabo la iniciativa en cuestión (Alzaga, 1978). Sin embargo, se constata que los Reglamentos exigen que la propuesta de una revisión constitucional ha de ser presentada, yendo suscrita por dos Grupos Parlamentarios o por una quinta parte de los diputados (art. 146 RCD), en el caso que se trate de iniciativa del Congreso; o bien por 50 senadores, que no pertenezcan al mismo Grupo Parlamentario (art. 152 RS), para las Proposiciones de Ley del Senado. Por lo que, aunque no puede hablarse de una rigidez propiamente dicha ya en fase de iniciativa de reforma ya que la prescripción del $166 \mathrm{CE}$ no establece dificultad adicional que supusiera algún grado de rigidez con respecto a la iniciativa legislativa ordinaria. Sin embargo, tal previsión reglamentaria presupone en sí un obstáculo, que de alguna manera dificulta la iniciativa de reforma en relación a la iniciativa 
legislativa ordinaria que interpretamos, como una intención del Constituyente de diferenciar los dos procedimientos ya en su inicio y que pone de relieve la especial trascendencia del instituto de reforma, con respecto al procedimiento de elaboración de las demás leyes ordinarias.

\section{TITULARIDAD DE LA INICIATIVA DE REFORMA.}

En relación a la titularidad de la iniciativa de reforma, cabe plantearse con De Vega dos ámbitos a analizar (De Vega, 1985:128):

1. La pluralidad de órganos que asumen dicha iniciativa.

2. La exclusión explícita de la iniciativa popular.

En relación al primero, considera Loewenstein que la distribución de la participación en la iniciativa de reforma entre diversos órganos confiere mayor legitimidad a esta función y, de otro lado y como vimos antes, disipa en parte el riesgo de que un solo poder saque ventaja de esta función de reforma. En cuanto a la segunda cuestión, la exclusión de la iniciativa popular en el proceso de iniciar la función revisora es un tema muy controvertido, puesto que sí se contempla dicha intervención popular en la iniciativa legislativa ordinaria, mientras se omite en la actuación del poder constituyente constituido de reforma.

Esta aparente paradoja pone de relieve una tensión entre democracia representativa y democracia directa, latente en nuestro ordenamiento, que ya se evidenció en el proceso del debate en la Comisión Constitucional del Congreso, con ocasión de la discusión sobre el referéndum, en que la iniciativa popular sería excluida, en consideración a la eventual discordancia de una iniciativa popular en el marco de la democracia representativa, así como por los riesgos que podría implicar su uso plebiscitario. En apoyo de su inclusión, Fraga Iribarne invocó que las circunstancias entre la iniciativa popular para el supuesto de referéndum eran muy distintas a las de la inclusión de la iniciativa popular para la reforma.

A este efecto y frente a la posición mantenida por Pérez Royo ${ }^{4}$, convenimos con De Vega ${ }^{5}$ y Vera Santos ${ }^{6}$ en que las instituciones de democracia directa no implican necesariamente una suplantación de la democracia representativa. Así, en este supuesto concreto, el ejercicio del referéndum se materializa en la ratificación de un acto de las Asambleas, mientras que en el caso

\footnotetext{
4 Pérez Royo, 1987:437.

5 De Vega, 1985:137.

${ }^{6}$ Vera Santos, 2007:137.
} 
de la iniciativa legislativa de reforma, simplemente intenta poner en marcha al poder legislativo conforme a los mecanismos de la democracia representativa.

Por ello no se comprende que nuestra Constitución, que invoca la soberanía popular, excluya la iniciativa popular en los procesos de reforma.

\subsection{Iniciativa del Gobierno.}

Ésta parte de la presentación de un proyecto de reforma por parte del Gobierno, una vez aprobado en Consejo de Ministros ante el Congreso, junto a una exposición de motivos. Aunque la Constitución alude sólo a proyectos de reforma constitucional, esta prescripción ha de entenderse, como afirma Vera Santos ${ }^{7}$ y a su vez Pérez Royo ${ }^{8}$ en sentido amplio, considerando que aunque el artículo 167 hace referencia únicamente a los proyectos de ley, como de técnica exclusivamente gubernamental, sin embargo, el constituyente le atribuye un carácter genérico, incluyendo todo tipo de textos legislativos enviados a las Cámaras al margen de que su procedencia sea estrictamente gubernamental, parlamentaria o de procedencia de las Asambleas legislativas de las Comunidades Autónomas. Así lo corrobora el Consejo de Estado ${ }^{9}$, al reconocer que la expresión "proyectos de ley» ha de entenderse genéricamente a todos los textos enviados a las Cortes, al margen de su específica procedencia.

\subsubsection{La singular intervención del Consejo de Estado en la iniciativa de Reforma}

Como órgano consultivo del ejecutivo, el Consejo de Estado, conforme interpretación del Tribunal Constitucional, ${ }^{10}$ es un órgano de relevancia constitucional, diferente pues de un órgano constitucional (art. $107 \mathrm{CE}$ ), tal y como lo considera igualmente la doctrina ${ }^{11}$.

Conforme al artículo 2 de la LOCE, el Consejo de Estado «realizará por sí o bajo su dirección los estudios, informes o memorias que el Gobierno le

7 Vera Santos, 2007: 201.

8 Pérez Royo, 1987:437.

9 «Debe entenderse en su sentido más amplio, como denominación genérica comúnmente utilizada para referirse a los textos en los que se concretan las iniciativas legislativas, con independencia de que técnicamente se trate de proyectos o proposiciones», $\mathrm{p}$. 337, Informe del Consejo de Estado sobre las modificaciones de la Constitución española, Madrid, 2006.

10 STC 56/1990, de 29 Marzo, FJ 37.

11 S. Romano (1898) seguido aquí por Gómez Montoro (1992). 
solicite y elaborará las propuestas legislativas o de reforma constitucional que el Gobierno le encomiende» ${ }^{12}$. Como vemos este precepto atribuye al Consejo la competencia para elaborar propuestas legislativas hasta de reforma, teniendo como único límite en la preparación del texto de sus propuestas el respeto a las directrices marcadas por el Gobierno. La modificación operada así en este órgano de «relevancia constitucional» y en consecuencia sin capacidad de dirección política, suscita en la doctrina amplia extrañeza y crítica. Esta es la opinión, entre otros, de Vera Santos ${ }^{13}$, postura crítica a la que me adhiero, en tanto que la reforma confiere al Consejo de Estado una función que no le correspondería, como señala González-Trevijano ${ }^{14}$, pues si la elaboración de propuestas legislativas tiene un claro componente de dirección política, ¿qué no decir en el caso de propuesta de reforma?

En este orden de cosas, por acuerdo del Consejo de Ministros de 4 de marzo de 2005, el Gobierno remitió una consulta al Consejo de Estado de la que se deduce que solicita de él la elaboración de una propuesta de reforma constitucional. La respuesta del Consejo de Estado fue tan hábil como sutil, al reflejar en su informe que el Gobierno no le ordenó una reforma constitucional, sino lo que le encomienda es elaborar un estudio o informe, toda vez que «[e]1 acuerdo adoptado es, en efecto, el de solicitar del Consejo de Estado un «informe sobre (...) modificaciones de la Constitución Española», sin encomendarle -como también habría podido hacer- la elaboración de una o varias «propuestas de reforma constitucional». Esta opción ha sido, con seguridad, meditada y tiene un significado político que condiciona de manera decisiva la tarea encomendada al Consejo de Estado. No se le pide la redacción de textos que den forma jurídica a una reforma cuyo contenido está ya definido, sino un informe acerca de las modificaciones constitucionales que la consulta define solo por relación a los objetivos que el Gobierno considera deseables $\rangle^{15}$.

La respuesta del informe del Consejo de Estado autoriza a reafirmar que es al Gobierno a quien corresponde la iniciativa de reforma constitucional, no estando en ningún caso el Consejo de Estado habilitado a impulsar texto alguno de propuesta de reforma constitucional y que avala con dos de sus Dictámenes el Consejo de Estado ${ }^{16}$.

${ }^{12}$ Esta es la dicción tras la reforma operada por la Ley Orgánica 3/2004, de 28 de diciembre.

13 Vera Santos, 2007: 211.

14 González-Trevijano, 2006:15-42.

15 Informe del Consejo de Estado sobre las modificaciones de la Constitución española, Madrid, 2006, p. 12.

${ }_{16}$ Dictamen 47451 de 19 de junio de 1985 y Dictamen 307/1996, de 4 de Septiembre, en el que señala que «cuando se trata de elaborar una ley el dictamen se ha de constreñir 


\subsection{Iniciativa del Congreso y del Senado.}

El agravamiento de los requisitos exigidos para el Congreso y el Senado para afrontar la reforma en comparación con los que se sigue para el procedimiento legislativo ordinario se entiende desde la loable pretensión de alcanzar el mayor consenso posible entre las fuerzas políticas para acometer aquélla.

En todo caso, conviene señalar que a pesar de lo previsto en el artículo 87 $\mathrm{CE}$, la iniciativa de la reforma, en rigor, no corresponde al Congreso ni al Senado, sino que, conforme a los artículos 146 y 152 de los Reglamentos del Congreso y del Senado, respectivamente, son 75 Diputados y 50 Senadores quienes ejercitan realmente la iniciativa de reforma, mientras que las Cámaras, como órganos colegiados, lo que hacen, expresando una voluntad unitaria, es decidir sobre las iniciativas ajenas del Gobierno y de las Asambleas de las Comunidades autónomas ${ }^{17}$.

La cuestión se cifra en el hecho de que nuestra Constitución no diferencia entre iniciativa propiamente dicha y la decisión de las Cámaras en torno a dicha iniciativa, es decir, que no se excluye que las Cámaras puedan rechazar la oportunidad de la reforma propuesta a iniciativa del Gobierno o de las Asambleas de la CCAA y sobre las propuestas de los parlamentarios aisladamente considerados.

\subsection{Iniciativa de las Asambleas de las CCAA.}

El artículo 87.2 CE muestra la doble vertiente por la que las asambleas autonómicas pueden hacer uso de su iniciativa legislativa y, específicamente, en materia de revisión constitucional, ya sea por vía gubernamental -a través de la solicitud al Gobierno de la adopción de un proyecto de ley- ya a través de Congreso - por medio de la presentación ante la Mesa de éste, de una proposición de ley.

La intervención de estas asambleas en la iniciativa de reforma, en tanto que perfila una solicitud al gobierno de la adopción de un proyecto de ley, no pasa de ser un derecho de petición (Alzaga Villaamil, 1978:564), sin efectos vinculantes para el gobierno, pues un simple derecho de petición, difícilmente puede asumir carácter obligatorio para el órgano al que va dirigida la misma. Pero, aún así, las dificultades de que se ha revestido tal iniciativa autonómica han sido consideradas insuficientes por cierto sector de la

a la constitucionalidad del anteproyecto, a su coordinación con el resto del ordenamiento y a cuestiones formales o de técnica normativa».

$17 \mathrm{Y}$ también sobre las propuestas surgidas de los parlamentarios, individual y aisladamente considerados, como afirma De Vega, 1985:133. 
doctrina en relación al posible diseño que hubiera podido asumir como, por ejemplo, la existencia de un determinado número mínimo de Comunidades Autónomas para presentar una solicitud de revisión, en consideración a las delicadas repercusiones que puede comportar una iniciativa de carácter autonómico, lo que aconseja diferenciarla con alguna exigencia adicional, de la iniciativa legislativa ordinaria (De Esteban y López Guerra, 1980:288).

En todo caso, la calificación jerárquica de tales órganos en la iniciativa de un proceso de reforma ha suscitado enfrentamiento en la doctrina por lo paradójico que es otorgar esta específica función a un órgano que no tiene conferido rango superior al de ley orgánica y negárselo a la iniciativa popular en nuestro sistema democrático.

\subsection{Exclusión de la iniciativa popular.}

No deja de extrañar que nuestro ordenamiento que proclama la soberanía popular excluya la iniciativa popular en el supuesto de iniciativa de reforma, máxime cuando equipara, en lo demás, la iniciativa legislativa con la de reforma. En este punto, discrepamos respecto a la justificación de dicha exclusión debido a la disfuncionalidad de una manifestación de democracia directa a través de la iniciativa popular en el marco de la democracia representativa, tal como quedó patente en el curso del debate en Comisión constitucional del Congreso, con ocasión de una enmienda presentada por UCD y apoyada por el PSOE y $\mathrm{PC}^{18}$.

Se ha dicho que cabe siempre un riesgo en la utilización de las instituciones de democracia directa, cuando no son practicadas como instrumentos de control de los órganos representativos (De Vega, 1985:137), al atribuírseles una legitimidad superior - tal como podría suceder en estas instituciones de democracia directa como el referéndum, o la iniciativa popular. No obstante, entendemos que hay que diferenciar entre ellas porque en el caso del referéndum constitucional, estaríamos ante el supuesto de ratificación de un acto de las Asambleas, mientras que la iniciativa popular pretende sólo activar el poder legislativo, mientras que, por su parte, el poder legislativo, puede tomar tal iniciativa en consideración, o bien, rechazarla.

En ambos casos, el poder constituido conforme a los mecanismos de democracia representativa, quedan incólumes, y en consecuencia, parece desproporcionado eliminar, -ante una eventual e hipotética mala utilizacióninstituciones de democracia directa, tales como la iniciativa popular y sin embargo, incluir el referéndum, aunque fuera facultativo, teniendo en ambos

${ }_{18}$ Trabajos Parlamentarios de la Constitución española, Vol. II, p. 1730, Diario de sesiones del Congreso de Diputados. Comisión de asuntos constitucionales y Libertades Públicas, Sesión 20 junio1978, núm. 24. 
casos, el mismo potencial peligro de suplantación de la democracia representativa.

Es, desde este planteamiento, incomprensible la exclusión de la iniciativa popular $166 \mathrm{CE}$, por varios motivos. En primer lugar, por la quiebra de la coherencia del ordenamiento constitucional, en la pretensión de conjugar el esquema representativo con los supuestos de democracia directa, como se desprende de los artículos 9.2 in fine («participación de todos los ciudadanos en la vida política, económica, social y cultural»); artículo 23.1 («Los ciudadanos tienen el derecho a participar en los asuntos públicos, directamente, o por medio de representantes...»); y el artículo 89 («sin que la prioridad de los proyectos de ley, impida el ejercicio de la iniciativa legislativa en los términos del artículo 87»), como puso Fraga de relieve en la mencionada sesión de 20 de junio al señalar que era una gran incongruencia la supresión de la iniciativa popular, en nombre del principio de la soberanía popular y de democracia directa por otra parte. Como afirma Vera Santos resulta paradójica la aceptación de una institución de democracia directa, aunque sea facultativa, del referéndum y omita la intervención directa de la soberanía popular para la iniciativa de la reforma constitucional (Vera Santos, 2007:137).

En segundo lugar, carece de base justificar esta omisión de la democracia directa por vía de la iniciativa popular en la reforma constitucional invocando potenciales riesgos de demagogia, como apunta De Vega, pues como afirma el mencionado autor, los mayores atentados a la democracia representativa no han derivado de la intervención directa popular, sino que los ataques al sistema constitucional se han producido por igual con iniciativa popular en la reforma, o sin ella, siendo la exclusión de la misma, un error del constituyente en la regulación del instituto de la reforma constitucional (De Vega, 1985:138).

En tercer lugar, entendemos, conforme afirma Loewenstein, que la competencia para activar la reforma constitucional ha de estar lo más distribuida posible, debiendo ser, uno de los elementos activos clave el pueblo organizado como electorado (Contreras, 1979:410). Además, al tratarse de la mera iniciativa, las Cortes podrían, con posterioridad, aprobar dicha iniciativa, o bien rechazarla, por lo que resulta excesiva la cautela del constituyente en el proceso de iniciativa.

Por último, cabe mencionar como posible explicación a la omisión de la iniciativa popular por parte de nuestro constituyente el que es posible justificarla atendiendo a la idea de que la supremacía de la Constitución. Es decir, en tanto que ésta es obra del poder constituyente, que se justifica por sí mismo y, puesto que su titularidad pertenece a la soberanía popular, se reconocería que esta opción de la iniciativa popular, no siendo jurídica su fundamentación, subyace siempre latente. Así, la nación en cuanto titular del poder constituyente, y a diferencia de los poderes constituidos, que pertenecen al 
derecho positivo, se origina de manera espontánea y natural» (De Vega, 1985:29).

Esta exclusión de la intervención de iniciativa popular hay que relacionarla con la tensión existente entre el poder constituido que como poder jurídico, hunde sus raíces en la constitución de la que deriva, frente a lo que acontece con el constituyente que, por su naturaleza pre-jurídica «res facti, non iuris», es ilimitado, tanto en su voluntad como en su manera de manifestarse, siendo competente para ordenar el régimen jurídico y -a través del Derecho- la vida política del estado (Herrero y Rodríguez de Miñón, 2015: 15).

La revolución que originó Sieyès a través de la democracia representativa marcó un punto de inflexión por el que el poder constituyente, como titular indiscutible de la soberanía popular, se traslada a la Asamblea en la que la Nación delega sus competencias.

Frente al planteamiento de Sieyès, son frecuentes los ordenamientos que, siguiendo la tradición americana, adoptan instituciones de democracia directa, como instrumentos limitadores del carácter soberano de otros órganos representativos. Por ello no se comprende que nuestra Constitución, que proclama la soberanía popular, y que al asumir el referéndum como instrumento de control en los procesos de reforma, de cierto modo condiciona el poder ilimitado y soberano de las asambleas representativas en los procesos de reforma, suprima expresamente la iniciativa popular. Con ello se produciría una tensión entre el poder constituyente y la democracia representativa que se traduce en lo siguiente:

- De una parte en nuestro ordenamiento, el poder constituyente no radica sin más, en las asambleas representativas, como sostenía Sieyès, en cuanto que su actuación en la reforma constitucional, necesita de ratificación popular por referéndum.

- Pero de otro lado, el poder constituyente no se centra de manera plena en el pueblo, ya que se excluye expresamente la iniciativa popular en la iniciativa para la reforma constitucional, y como es sabido, un poder sometido a limitaciones, no sería poder soberano.

No obstante, no han faltado quienes han encontrado razones a favor de la exclusión de la intervención popular en la iniciativa de reforma de la Constitución, invocando argumentos avalados por la conveniencia de afianzar el sistema de Democracia representativa en un país como España, cuya tradición democrática es escasa (Pérez Royo, 1987:149). Se esgrimiría así la inoportunidad de la iniciativa popular, por la falta de arraigo de la, aún bisoña, democracia parlamentaria, por el riesgo que podría implicar que las fuerzas sociales impidieran la implantación efectiva de una democracia 
representativa, subordinando a ella, uno de los mecanismos uno de los mecanismos básicos del sistema de garantías constitucionales, como es el instituto de reforma constitucional.

\subsection{Conclusión sobre la exclusión de iniciativa popular en la actividad de la reforma.}

Conforme a lo anteriormente indicado, entiendo que hurtar a la iniciativa popular su intervención en materia de iniciar un proceso de reforma contraviene un principio básico de coherencia de nuestra Norma fundamental, que pretende conjugar el modelo de democracia representativa con supuestos de democracia directa y participación directa de los ciudadanos, que pueden jugar un papel complementario -si no determinante- y no como papel sustitutivo del sistema representativo.

Finalmente, la exclusión de la iniciativa popular en la reforma proyecta una cierta concepción desviada de la noción del poder constituyente, patente en la exclusión de aquélla en la reforma, toda vez que el poder constituyente se manifiesta en la misma como constituido, lo que supone cerrar la puerta a la posibilidad de que el poder constituyente -soberano e ilimitado- interviniera como tal a través, directamente, de la iniciativa popular.

Por todo ello, no se entiende bien la supresión de una manifestación de la democracia directa por vía de iniciativa legislativa en la reforma constitucional, máxime cuando realmente es quien asume la titularidad del poder constituyente. Consideramos que se perdió una legítima oportunidad para dejar abierta la posibilidad de actuar a la soberanía popular a través de la iniciativa legislativa en la apertura de la reforma constitucional.

\section{CONSIDERACIONES SOBRE LA CONVENIENCIA O INOPORTUNIDAD DE REFORMA CONSTITUCIONAL.}

Con frecuencia hemos hablado y escuchado comentarios acerca de la necesidad de reformar nuestra Constitución de 1978, incluso al poco de ser promulgada, respecto al Senado (Torres del Moral, 2016).

Negar que nuestra Constitución no adolece de defectos técnicos y prescripciones sería negar la evidencia. Por ejemplo, podría incrementarse el número de Diputados para lograr mayor proporcionalidad entre votos y escaños, limitar a dos mandatos consecutivos del Presidente del Gobierno, reducir del número de firmas de la iniciativa popular, aumentar el ámbito de incompatibilidades de los Parlamentarios, etc. Ahora bien, es conveniente acotar el campo de reforma: 
- Porque no todas las reformas institucionales son precisas o convenientes (la modificación de la parte dogmática fue propugnada por varios partidos políticos en sendos programas electorales, así como la sucesión a la Corona, planteada en la consulta de Rodríguez Zapatero al Consejo de Estado en 2005, que dio lugar al informe de 2006 del Consejo de Estado, entre otras).

- Porque la prudencia política aconseja que muchas de las modificaciones propugnadas deben acometerse paulatinamente.

- Porque no todas las modificaciones de alcance constitucional deben hacerse en el mismo momento político y, por tanto acometerse al unísono (Herrero y Rodríguez de Miñón, 2016:46).

Desde estas consideraciones se podría diferenciar distintos ámbitos de eventuales reformas, como afirma el autor, cuyo tratamiento sería diferente, en función de la materia.

- Así, en primer lugar, estarían aquellas reformas que no serían oportunas ni convenientes, cual sería el caso de alguna de las propuestas relativas a la parte dogmática de la Constitución y sucesión a la Corona.

- En otro lugar, estarían aquellas reformas que pueden acometerse sin necesidad de una modificación formal de la Constitución, pudiendo integrar en este bloque al sistema electoral, así como a los partidos políticos, la Administración de justicia, el Senado y la laguna existente en torno a derechos de última generación, entre otros.

- Finalmente, estaría el grupo de las modificaciones que pudieran ser convenientes, pero que no están aún maduras para acometerse con éxito, como la constitucionalización de la pertenencia de España a la Unión Europea, así como la organización territorial del Estado si bien esta última tratada por separado.

a) En relación al primer grupo:

La parte dogmática configuró la parte más difícil de la redacción del texto. Fue gestada con gran consenso, reiterada por la interpretación constitucional y en la actualidad cabe distinguir diferentes generaciones de derechos que mantienen tratamiento diferencial en función de sus nivel de garantías, diferenciando entre derechos fundamentales y libertades públicas y derechos sociales. Como es sabido, siendo ambos vinculantes para los poderes públicos, sólo los primeros son tutelables directamente por los tribunales, mientras que los segundos, son exigibles conforme a las leyes que los desarrollan.

En este sentido, compartimos la opinión del sector de la doctrina que considera innecesaria su reforma, por entender que el grado de eficacia en su 
ejercicio no depende tanto de su revisión material, como de las políticas que a medio plazo se adopten en diversos ámbitos técnico-sanitarios, sociales, culturales y económicos, respecto a los que la constitución proyecta una orientación política, pero que corresponde a los poderes públicos ponerlas en práctica.

En lo que respecta a la no discriminación por razón de género relativa a la sucesión de la Corona, la eliminación de la cláusula de varonía, en una sociedad que está siendo golpeada por frecuentes episodios de violencia machista, no deja de tener un mero valor simbólico, cuando además, de momento son dos niñas las llamadas en el orden sucesorio. No parece, pues, urgente la situación sucesoria y como está posiblemente asegurado el orden sucesorio a favor de una mujer, dado que el procedimiento de reforma que sería por vía de procedimiento agravado y que, por lo demás, tampoco parece que apasione tanto a la opinión pública. Abrir una reforma en lo que concierne al Título II, seguramente, provocaría un debate sobre la Monarquía Parlamentaria como forma de Jefatura de Estado, lo que no sería nada conveniente para la estabilidad política, particularmente en estos momentos en los que se escriben estas líneas -Octubre 2017- en plena crisis de golpe de Estado en la Comunidad Autónoma de Cataluña.

b) En relación al segundo grupo:

No se requeriría reforma, por ser posiblemente viable su adecuación por otras vías, tal y como operaría un cambio institucional (Urcuyo Fournier, 2013:54). De acuerdo con Torres del Moral, la regeneración democrática depende mucho más de la legislación sobre partidos (que incluya una democracia interna real), de los Reglamentos parlamentarios (que posibiliten facilidades a los grupos minoritarios en el ejercicio de la función de control del gobierno o que impongan una mayor presencia del Gobierno en las Cámaras) o del freno a la corrupción política, más que del ajuste decimal de la ratio voto /escaño (Torres del Moral, 2016:10). Por ello, bien puede procederse a cambiar lo necesario, partiendo de una legislación subconstitucional, como sería así mismo el caso de la reforma de la LOREG para lograr, por ejemplo, una mayor proporcionalidad en el valor del voto entre las provincias o bien evaluando la incidencia de la fórmula de escrutinio D'Hondt o del resto mayor, con la certeza de que pueden conseguirse convenientes resultados que hagan innecesaria, o al menos no urgente, la apertura de un procedimiento formal de reforma constitucional en la inmediata actualidad.

Y en esta línea se sitúa la propuesta de reforma del Senado que, como Cámara de representación territorial, no ha logrado sin embargo, configurarse como Cámara de representación de las poblaciones de los distintos territorios del Estado ni logró el protagonismo institucional suficiente. 
La función de revisión legislativa del Senado autonómico con frecuencia reitera la tensión entre los partidos representados en el Congreso y los que controlan unas y otras autonomías, por lo que cabe concluir que la eficacia y arraigo de las instituciones representativas depende más del diseño de sus funciones y de sus dinámicas de funcionamiento, siempre que el sistema electoral sea el adecuado a un régimen democrático.

La disconformidad de la opinión pública, con carácter general, con nuestro Senado, no es tanto por el sistema a través del que son elegidos los senadores, como pone de relieve Torres del Moral, sino por su configuración constitucional, que no consiguió hacer de él una Cámara con el suficiente protagonismo institucional y representatividad de las provincias de los distintos territorios del Estado (Torres del Moral, 2016:11).

En relación a la laguna Constitucional de los derechos de última generación derivados de los adelantos y progresos de la biomedicina y que afectan a la más absoluta intimidad de las personas y con efectos erga omnes, hay que tener presente que comporta una problemática ética y jurídico-constitucional relevante. Es decir, hay que evitar que el progreso arrolle el principio de dignidad humana, pero hay que evitar posibles barreras al avance científico. En consecuencia, estos aspectos podrían reconducirse sin necesidad de reforma formal de la Constitución.

c) Respecto al tercer grupo:

Se hace precisa una reflexión en torno a la conveniencia o inoportunidad sobre la constitucionalización de la pertenencia de España a la UE en virtud de la cual, los Estados miembros aceptan la existencia de unos principios inmanentes que informan su ordenamiento. La integración de España a la UE se vinculó a la transición a la democracia y por ello se ha entendido siempre como un valor entendido que implica, necesariamente, la adopción de tales principios aún de manera implícita, lo que haría tal vez conveniente, pero no necesaria, su incorporación material a nuestro texto constitucional en la actualidad, máxime, en momentos de tensión en el corazón europeo con importantes discrepancias nacionales en asuntos tales como la presión migratoria.

\section{LA ORGANIZACIÓN TERRITORIAL DE ESTADO. EL GRAVE PROBLEMA CATALÁN.}

La estructura territorial del Estado de las autonomías proyecta una duplicidad de estructuras e instituciones que conduce a reproducir el Estado a menor escala, multiplicando las instituciones por el número de autonomías.

La distribución de competencias que se han sumado en un nivel, sin haberse rebajado en otro, han aumentado la tensión, el coste y generado una 
confusión tal, que se requiere de una precisa distribución de las mismas, sin trato desigual para ninguna Comunidad, pero atendiendo a sus hechos diferenciales.

El traje autonómico que diseñó el constituyente se ha quedado corto porque, en realidad, nadie entonces sabía cuántas iban a ser, ni cómo, ni con qué se iban a elaborar sus Estatutos, ni con qué competencias, hasta el punto de reconocerlo como un Estado de las Autonomías desconstitucionalizado. La cuestión es de suficiente entidad y de complejo tratamiento como para abordarlo mediante una reforma global, como se ha propuesto en ciertos foros.

El problema que se ha generado entre el Gobierno y la Comunidad autónoma catalana exige una solución de extrema urgencia e inmediatez, lo que, en modo alguno, podría resolverse con la urgencia que las actuales circunstancias permitiría, a través de un procedimiento de reforma constitucional, conforme a lo previsto en nuestra Constitución por el cauce de los artículos 167 y 168 CE.

El Estatuto de Autonomía de Cataluña de 1979 fue un verdadero pacto de Estado más que una Ley Orgánica como cualquier otra, como se reveló con la frustrada LOAPA, que a pesar de ser rechazada por el Tribunal Constitucional en sentencia 76/1983 propició una progresiva administrativización de la autonomía política recentralizadora, marginando en buena medida la identidad histórico-social del pueblo catalán que es, en esencia, lo que legitima su auténtico derecho de autogobierno (Herrero y Rodríguez de Miñón, 2016:98).

El desafío nacionalista-secesionista que el Gobierno de la Generalidad viene manteniendo con el Gobierno Central con los trágicos y lamentables sucesos que han permitido un resquebrajamiento en la sociedad catalana y en el resto de la sociedad española requiere de una urgente solución con la idoneidad de los instrumentos que la Constitución ofrece por la vía del artículo 155. Pero, además, se requiere de una firme decisión política -no necesariamente jurídica- para interpretar el hecho diferencial catalán, tanto en términos fiscales, competenciales e identitarios que se traduzca en una política de reconocimiento de dicha particular autonomía para terminar con la más absoluta desafección por buena parte de la sociedad catalana y con el, permanentemente latente, y el, a día de hoy, revolucionario, desafío independentista.

\subsection{Posible modificación informal de la previsión constitucional en el caso catalán.}

La búsqueda de la fórmula magistral para el reconocimiento constitucional de la identidad catalana en términos de reafirmar su voluntaria integración frente a la secesión, creemos que en la actualidad, no pasa por una reforma constitucional. El problema es de tal envergadura que ha de tratarse 
de manera individual y aislada para preservar la capacidad particular que la realidad singular catalana requiere.

En momentos de gran convulsión como los que está pasando la sociedad española con carácter general, y la catalana muy particularmente, y que comportan un grave resquebrajamiento de la pacífica convivencia social, política y económica -son bastantes las empresas que cambian su sede social a otros lugares fuera de la Comunidad Autónoma de Cataluña- parece absolutamente improcedente, siquiera, plantear una reforma de la Constitución que solucionara el malestar de dicha Autonomía por las reivindicaciones solicitadas al Gobierno de la Nación y no del todo satisfechas.

Si se tiene voluntad de resolver la problemática catalana, que nos duele a todos los españoles y por la que abogamos la mayoría de los ciudadanos que, ajenos al independentismo, deseamos una pacífica, justa y racional convivencia dentro del marco diseñado por el artículo $2 \mathrm{CE}$ ( «La Constitución se fundamenta en la indisoluble unidad de la Nación Española, patria común e indivisible de todos los Españoles y reconoce y garantiza el derecho a la autonomía de las nacionalidades y regiones que la integran y la solidaridad entre todas ellas») habrá que ir paso a paso en un ejercicio de reconducción de la situación al marco de la legalidad. Esta senda de la que nunca se debió salir, configura en sí ya un largo camino de recuperación y reconstrucción política y social, y a partir de ese punto y en el escenario de la más estricta legalidad constitucional, cabría restablecer -por vía del artículo $155 \mathrm{CE}$, si se diera la circunstancia de una DUI- la normalidad constitucional. A partir de ese momento, se darían las circunstancias para que se pueda pactar, entre el Gobierno central y un nuevo Gobierno de la Generalitat -desde la posición correspondiente, y sin ser una mediación-el cauce idóneo para el logro de las aspiraciones que derivan de sus derechos históricos y el adecuado reconocimiento del techo competencial de la autonomía catalana, dentro de la legalidad constitucional.

El Derecho constitucional no está ayuno de fórmulas jurídicas y políticas para su oportuna aplicación práctica, si se tiene voluntad para ello. Esta vía no requeriría necesariamente activar la reforma constitucional conforme a los artículos 167 y $168 \mathrm{CE}$ por los riesgos políticos y técnicos que hoy supondría acometerla, en los momentos de convulsión que se viven.

En este sentido nos adherimos a la posición del sector de la doctrina que invoca la modificación de determinados ámbitos por otras vías. Así, en el caso de Torres del Moral se defiende una modificación de Reglamentos y leyes orgánicas, como vimos anteriormente, o bien, en el supuesto de Herrero y Rodríguez de Miñón, se plantea la vía de alterar la Constitución pero sin modificar su texto, figura reconocida como mutación, práctica constitucional al objeto de reordenar las relaciones de las instituciones previstas en la Constitución y que, en suma, supone una modificación indirecta de la Norma 
Fundamental, conforme a la doctrina germana (Torres del Moral, 2016:13 y Herrero y Rodríguez de Miñón, 2016:98).

De entre los diversos tipos de mutación aludidos por Loewenstein, posiblemente, nos encontraríamos ante el supuesto de una práctica constitucional que no viola la Constitución pero respecto a la que no existe una precisa norma afecta al caso y que cabe resolverse a través de una particular interpretación de una prescripción constitucional. Convenimos en que esta vía de mutación por convención, como un Pacto de Estado con la Generalidad, podría ser la menos laboriosa de las dos mencionadas si se aplicara a Cataluña, siempre que se llegara al acuerdo consensuado y pactado, y posteriormente aprobado en Referéndum por el pueblo Catalán, conforme al artículo 152 apartado 2, incorporando dicho pacto por vía de una nueva Disposición adicional, conforme a lo previsto en la Disposición Transitoria segunda de la CE.

\subsection{Seguridad jurídica y límites de la modificación informal de la Constitución.}

A pesar de ser ésta una posible vía -mutación convencional-para reconducir la situación institucional y la normalidad de la autonomía catalana, habrá que estar muy precisos a efectos de definir los límites de la modificación de la normativa por mutación convencional de la Constitución, tanto para evitar fraudes de la Constitución, como por los eventuales riesgos de inseguridad jurídica. Como estudio en otro trabajo, hay que garantizar el texto básico que vertebra el resto de la normativa constitucional ya que, al tratarse la mutación convencional de una práctica extra jurídica (Loewenstein, 1965:165), carece de la seguridad que confiere una prescripción formalmente consolidada en el texto (García-Atance, 2002:98).

En tal caso, para controlar las alteraciones informales habrá que recurrir a unos límites que tuvieran la doble finalidad:

- De un lado, de Protección de la Norma que identifica un determinado orden constitucional y cuyo desbordamiento tipificaría un cambio de Constitución, impensable por vía de mutación.

- De otro, la delimitación que tuviera por objeto diferenciar entre las mutaciones contra constitutionem, frente a aquellas otras que asumen una condición perfectamente praeter constitutionem.

Desde esta consideración, cabe afirmar con un sector de la doctrina, la existencia de límites a la praxis de la modificación constitucional informal por mutación, para evitar el conflicto entre lo normativo y lo fáctico, soslayando así la situación que derivaría en incompatibilidad manifiesta entre 
ambas realidades (De Vega, 1985:214). En este sentido, habrá que acoplar, como sostienen Hesse y Mortati, el contenido y la comprensión del texto de la Norma Constitucional con su modificación por vía informal, producidas por la propia dinámica evolutiva de la vida social (Hesse, 1983:109; Mortati, 1962:61).

Desde esta óptica, se podría apreciar si la modificación informal acometida desde este cauce goza del apoyo suficiente para consolidarse como tal y proceder a una reforma constitucional formal a medio plazo; o bien, podría priorizarse el efecto fáctico y asumir la idea del «fait accompli», prevaleciendo la vía informal sobre la jurídica, siempre que se respeten los límites de esta actividad informal de modificación.

La finalidad del orden constitucional es la de integrar a la sociedad en la indisoluble patria común e indivisible, reconociendo y garantizando la singularidad de las comunidades autónomas conforme a su Estatuto de Autonomía y sus derechos históricos. Según esto, el Estado asume la voluntad y obligación del reconocimiento identitario de la Comunidad Autónoma, con la consiguiente atribución de competencias, conforme al techo que el grado de soberanía autonómica tenga la comunidad, y pactando, conforme a ello, en un acto de co-decisión, con lo que se reconocería en este derecho a co-decidir un cierto concurso de co-soberanía (Herrero y Rodríguez de Miñón, 2016:101).

Sin pretensión alguna de minimizar atribuciones reconocidas competencialmente a la Comunidad catalana, entendemos que aún siendo, posiblemente, la idea del pacto la mejor vía de solución, resulta difícil entender la figura de un pacto, en un mismo plano de igualdad, entre un Estado soberano, como tal, y una Comunidad autónoma. Y ello aunque tal Comunidad, como en el supuesto catalán, tenga su Estatuto de autonomía de 1979 que siempre tuvo un especial reconocimiento y el Estatuto de 2006, cuyo vigente artículo 5 no anuló el TC en su Sentencia de 2010. Además, en este caso estarían claramente reconocidos sus derechos históricos, al haber plebiscitado un Estatuto de Autonomía que estuvo vigor desde 1932 a 1936.

Entendemos que la articulación de distribución de competencias en un pacto de co-decisión no cabe ser entendido como pacto de co-soberanía -el lenguaje no es inocente. La idea de pacto de co-decisión es aceptable para articular los ámbitos competenciales de las nacionalidades y regiones pero no cabe olvidar el concepto de Estado soberano.

\section{BIBLIOGRAFÍA}

Alzaga Villaamil, O., La Constitución Española 1978. Comentario sistemático, Ediciones del Foro, Madrid, 1978.

BRYCE, J., Constituciones flexibles y Constituciones rígidas, CEPC, Madrid, 2015 (el estudio original, en inglés, fue publicado en 1901). 
Burdeau, G., Traité de Science Politique, Tome IV, LGDJ, Paris, 1969.

Contreras, M., «La reforma de la Constitución», Ramírez, M., Estudios sobre la Constitución Española de 1978, Libros Pórtico, Zaragoza, 1979, pp. 403-421.

Crisafulli, V., «Per una teoria giurídica nell'indirizzo político», Vol. XVII, Studi Urbinati, 1939.

DE CABO, C., La reforma constitucional en la perspectiva de las fuentes del Derecho, Trotta, Madrid, 2003.

De Esteban, J.; López Guerra, L., El régimen constitucional español, Labor, Barcelona, 1980.

De Otto Pardo, I., Defensa de la constitución y partidos políticos, CEPC, Madrid, 1985.

DE VeGA, P., La reforma constitucional y la problemática del poder constituyente, Tecnos, Madrid, 1985.

DUVERGER, M., Instituciones politicas y Derecho constitucional, $5^{\mathrm{a}}$ ed., Ariel, Barcelona, 1980.

EsmeIn, A., Élements de Droit Constitutionnel, 7ème ed., Recueil Sirey, Paris, 1921.

Friedrich, C. J., Gobierno Constitucional y Democracia, Instituto de Estudios Politicos, Madrid, 1975.

García-Atance García de Mora, M. V., Reforma y permanencia constitucional, CEPC, Madrid, 2002.

Gómez Montoro, A. J., El conflicto entre órganos constitucionales, CEPC, Madrid, 1992.

GonzÁlez-Trevijano SÁnchez, P. J., «La reforma como defensa de la propia Constitución», Cuadernos de pensamiento político FAES, núm. 11, 2006, pp. 15-42.

GonzÁlez-Trevijano, P., «La reforma como defensa de la propia Constitución», Cuadernos de Pensamiento Político, núm. 11, 2006, pp. 15-42.

Hamilton, A., Madison, J., Jay, J., El Federalista (trad. de G. R. Velasco, del original: The Federalist. A Commentary on the Constitution of the United States, 1780), FCE, México, $2^{\mathrm{a}}$ ed., 1957 (primera ed. 1943).

Herrero y Rodríguez de MiÑón, M., Tres Conferencias sobre la reforma constitucional, Tirant Lo Blanch, Valencia, 2016.

Hesse, K., Escritos de Derecho Constitucional, CEPC, Madrid, 1983.

Kelsen, H., Historia General del Derecho y del Estado, Textos Universitarios México, 1979.

Loewenstein, K., Teoría de la Constitución, Ariel, Barcelona, 1965.

Lucas Verdú, P., Curso Derecho político, Vol. II, Tecnos, Madrid, 1977.

Madison El Federalista XLIII. Para el diario Independiente. Prologo y versión G.R.Velasco. Fondo de cultura 1957México pag187 (los artículos originales que componen «El Federalista» datan del bienio 1787-1788).

Morlino, L., Como cambian los regímenes políticos (trad. de J. J. González Encinar), CEPC, Madrid, 1985.

Mortati, C., «Costituzione (Dottrine Generale)», Enciclopedia del Diritto, Giuffrè, Milano, 1962, Vol. XI.

-Istituzioni di Diritto Pubblico, Cedam, Padova, 1949.

-La Costituzione in senso materiale, Giuffrè, Milano, 1940. 
Pérez Royo, J., La Reforma de la Constitución, Ed. Congreso de los Diputados, Madrid, 1987.

Posada, A., Derecho Político, $4^{a}$ ed., Vol. II, Librería General de Victoriano Suárez, Madrid, 1929.

Romano, S., Nozione e natura degli organi costituzionali dello stato, Fratelli Marsala, Palermo, 1898.

Ruiz del Castillo y Catalán de Ocón, C., Manual de Derecho político, Reus, Madrid, 1939.

Schmiтt, C., La defensa de la Constitución, Tecnos, Madrid, 1983.

-Teoría de la Constitución, Alianza, Madrid, 1982.

SemPere, J. M., «La Reforma constitucional», Revista General de Legislación y Jurisprudencia, Vol. 55, núm. 110 (pp. 209-213) y núm. 111 (pp. 92-118, 246-270, 438-478), 1907.

SMEND, R., Constituciones y Derecho constitucional, CEPC, Madrid, 1985.

Spagna Musso, E., Diritto Costituzionale, Vol I, Cedam, Padova, 1979.

Tomás y Valiente, F., «La defensa de la Constitución», Revista de Derecho Político, núm. 16, 1982-83, pp. 185-192.

TORRES Del Moral, A., «Reforma Política y constitucional», Conferencia en Talavera, 8 abril 2016.

UrcuYo Fournier, C., «Reforma Política, ¿Última oportunidad? Ya no y todavía no», Revista Derecho Electoral, núm. 16 julio-diciembre 2013, pp. 47-76.

Vera Santos, J. M., La reforma constitucional en España, Ed. La Ley, Madrid, 2007. 